\title{
LA OLA AUTORITARIA Y EL EXTREMISMO EN EL MUNDO DURAกTE LA PARDEMIA DE COVID-19
}

\section{The Worluide Authoritarian Wave and Extremism during the COVID-19 Pandemic}

\author{
Rafael Moreno Valencia \\ Dirección General de Asuntos Internacionales del Gobierno del Estado de Jalisco \\ Asesor profesional en el corporativo de Seguros Monterrey New York Life \\ Email: rafael.moreno9560@alumnos.udg.mx \\ ORCID: https://orcid.org/0000-0003-4622-2883
}

La actual pandemia de COVID-19 ha tenido impactos económicos, políticos y sociales en el mundo. Sin embargo, la actual crisis sanitaria ha traído consigo otra pandemia: una ola creciente de autoritarismo y extremismo en muchas sociedades. Factores como crisis económicas, humanitarias o sociopolíticas han detonado polarización y malestar social, mientras que movimientos políticos han aprovechado estas crisis para llegar al poder o avanzar en sus agendas políticas. La crisis sanitaria no hizo más que agravar la deriva autoritaria ya existente mientras que los grupos extremistas han aprovechado la actividad y conectividad en línea de las personas confinadas para atraer a más seguidores y tomar acciones violentas a través de las redes sociales. Si crece la ampliación del poder y la autonomía de los Estados-nación durante la pandemia de COVID-19, junto con pocos contrapesos al interior, existen riesgos de efectos duraderos para la privacidad, la seguridad y la democracia de todos los países.

The current COVID-19 pandemic has had economic, political and social impact worlwide. However, the current health crisis has brought with it another pandemic: a growing wave of authoritarianism and extremism in many societies. Factors such as economic, humanitarian or socio-political crises have triggered polarization and social unrest, while political movements have taken advantage of these crises to come to power or advance their political agendas. The health crisis only exacerbated the already existing authoritarian tendencies meanwhile extremist groups have taken advantage of the online activity and connectivity of confined people to attract more followers and take violent action through social media. If the expansion of the power and autonomy of nation-states grows during the COVID-19 pandemic, along with limited checks and balances, there are risks of lasting effects on the privacy, security and democracy of all countries.

Autoritarismo; extremismo; nacionalismo; COVID-19; gobernanza; seguridad nacional. Authoritarism; extremism; nationalism; COVID-19; governance; national security.

Key words 


\section{Introducción}

La actual crisis sanitaria provocada por la pandemia de COVID-19 a inicios de 2020 ha impactado de manera disruptiva no solo la economía sino también la vida política y social de todos los países del orbe. Mientras se redacta este artículo, la emergencia continúa y con ella los confinamientos masivos en la mayor parte del mundo. Después de más de un año desde que la pandemia llegó al continente americano, se discuten los impactos que tendrá a futuro y si la vida que teníamos volverá a la normalidad o si cambiará para siempre. Sin embargo, el avance del coronavirus ha traído como consecuencia el surgimiento de una nueva pandemia: una creciente ola autoritaria y extremista en diversas sociedades.

Este fenómeno no es nuevo puesto que, desde antes del inicio de la pandemia, en diferentes latitudes ya se observaba la polarización en los últimos años como producto de eventos como crisis financieras y humanitarias, que han dado cabida a diferentes movimientos políticos que buscan tomar ventaja del clima de encono y malestar social para promover su agenda y llegar al poder.

Caracterizados por una narrativa extremista y bajo una lógica de "nosotros contra ellos", culpan de las desigualdades y frustraciones de la ciudadanía a los valores liberales y progresistas que se han difundido gracias a la globalización (Martínez, 2020). Bajo este discurso, grupos extremistas logran vincular el desprecio a estos valores con minorías o grupos sociales, migrantes o minorías éticas, a los que buscan estigmatizar para promover políticas iliberales y autoritarias, así como legitimar y normalizar discursos de odio en la sociedad (Martínez, 2020).

No es sorpresa que de las facciones más radicales que están ganando terreno en el mundo, las de mayor crecimiento sean las de extrema derecha categorizadas como ultraconservadoras, ultranacionalistas, supremacistas o xenófobas. Ejemplos son variados, en Europa, el partido gobernante de Polonia Ley y Justicia (PiS) ha emprendido políticas de pérdida de autonomía judicial y de libertad de prensa (Chouza, 2019), en Italia, la Liga (antes LigaNorte) ha impulsado políticas antiinmigración (Pasetti, 2018), en Reino Unido, el Brexit fue liderado por los conservadores Tories (Scott, 2020); la llegada al poder de Donald Trump y Jair Bolsonaro en Estados Unidos y Brasil respectivamente son señales de una creciente ola de nacionalismo en el mundo (Brooks, 2019).

La coyuntura actual de la crisis derivada de la COVID-19 no hizo más que agravar la deriva autoritaria ya existente en el mundo prepandemia. La crisis ha forzado a los mandatarios, incluso de las democracias más liberales, a declarar estados de emergencia que han coartado libertades civiles con tal de hacer frente a la propagación del virus, y han tenido no solo un impacto económico sino social, político y hasta psicológico en las sociedades. En los países menos democráticos, los gobiernos han sido más autoritarios y han aprovechado la crisis para consolidar su poder, atribuirse más competencias y avanzar en su agenda política (Aguirre, 2020).

Los gobiernos de China, Turquía y Tailandia han intensificado sus campañas en contra de la prensa libre, el activismo social, expulsado corresponsales extranjeros y perseguido a periodistas que se atrevan a criticar sus gobiernos durante la crisis sanitaria (Védeilhé et al., 2020; Hernández, 2020; Amnistía Internacional, 2020). El mandatario de Azerbaiyán, Ilham Aliyev, ha jurado "destruir" a los enemigos del país durante la pandemia, aprovechando la crisis para arrestar a opositores del gobierno (Human Rights Watch, 2020). Rodrigo Duterte, presidente de Filipinas, ha permitido a las fuerzas de seguridad disparar contra los civiles que violen la cuarentena (El País, 2020). Vladimir Putin, presidente de la Federación Rusa, ha justificado el
La coyuntura actual de la crisis derivada de la COVID-19 no hizo más que agravar la deriva autoritaria ya existente en el mundo prepandemia 
confinamiento para prohibir las protestas en contra de su gobierno y recientemente firmó una ley que le permitirá seguir en el cargo hasta 2036 (DW, 2020; Roth, 2021). Otros gobernantes como Xi Jinping o Narendra Modi en China y la India, han justificado la pandemia para hostigar a minorías étnicas como los uigures en Xinjiang o a los musulmanes en el norte de la India (Buckley, 2020; Reuters, 2020).

La ola autoritaria ya estaba presente en el mundo antes de la pandemia en países de Europa del Este. Tal es el caso de Hungría, país que ha sido gobernado por Viktor Orban y el partido Fidesz desde 2010, que ha promovido una agenda antiinmigrante, opuesta a las organizaciones de la sociedad civil, universidades privadas y las libertades fundamentales (Hopkins, 2020). En el actual contexto de la pandemia, Orban promovió un estado de emergencia que ahora le permite gobernar por decreto, aunado a ello ha cancelado las elecciones y ha avanzado en sus políticas antiderechos, como el de anular el reconocimiento a la identidad de las personas transexuales (Hopkins, 2020). En Latinoamérica, los presidentes de México y Brasil, Andrés Manuel López Obrador y Jair Bolsonaro fueron escépticos de la gravedad de la pandemia. El mandatario mexicano subestimó el uso del cubrebocas en público y el brasileño continuó organizando mítines políticos sin las medidas sanitarias que pusieron en riesgo la vida de miles de personas. Al día de hoy, México y Brasil son los epicentros de la pandemia con saldos de más de 200000 y 300000 muertes por COVID-19 respectivamente (Velásquez, 2021).

Por otro lado, actores que se creían desdibujados, han reaparecido tomando ventaja de la crisis causada por la COVID-19. Es el caso de Estado Islámico que ha llamado a sus seguidores a hacer uso de la crisis para planear y perpetrar ataques terroristas (EFE y APF, 2020). El terrorismo islamista también se ha hecho presente en países europeos como Francia que ha sido testigo de ataques con cuchillos en diferentes ciudades como París o Niza que han dejado víctimas mortales (DW, 2020). Pero desde que inició la pandemia, no solo han ocurrido ataques terroristas, también se han incrementado los crímenes de odio contra poblaciones asiáticas, minorías, inmigrantes, musulmanes y judíos en el mundo, especialmente en tiroteos en Estados Unidos y Canadá (Martínez, 2020).

\section{El retroceso de la democracia y el crecimiento del autoritarismo durante la pandemia de COVID-19}

La organización Freedom House (2020) ha reportado que desde la emergencia del nuevo coronavirus SARS-CoV-2 inició, la democracia y los derechos humanos han empeorado en 80 países, con un deterioro más agudo en democracias frágiles y estados altamente represivos. La crisis del coronavirus ha tenido un impacto en muchos aspectos de la democracia alrededor del mundo, desde la decisión de suspender elecciones hasta suspender las protestas ciudadanas (Glenn, 2020). Por ejemplo, de acuerdo con el Instituto Internacional para la Democracia y la Asistencia Electoral, debido a la pandemia de COVID-19, elecciones han sido pospuestas o canceladas en al menos 75 países o territorios (IDEA, 2021). No obstante, las tendencias globales del retroceso de la democracia datan de antes del inicio de la pandemia. El reporte anual de Freedom House, Freedom in the world, ya señalaba que 2019 era el año consecutivo número 14 que caía la libertad global (Repucci, 2020).

Estudios han demostrado que factores situacionales como las amenazas percibidas al orden social activan un latente autoritarismo (Hartman et al., 2021, p. 1). Se han encontrado correlacio-

\section{La organización}

Freedom House

(2020) ha

reportado que

desde que se inició

la emergencia del

nuevo coronavirus

SARS-COV-2, la

democracia y los

derechos humanos

han empeorado

en 80 países,

con un deterioro

más agudo en

democracias

frágiles y estados

altamente

represivos 
nes entre el autoritarismo y las actitudes nacionalistas y antiinmigrantes cuando hay niveles de amenazas percibidas (Hartman et al., 2021, p. 1) como la pandemia de COVID-19. Entonces, mientras la ansiedad de la pandemia crezca también se incrementa el efecto de autoritarismo en los resultados de políticas. Se puede deducir que las amenazas existenciales a la humanidad como la pandemia de COVID-19 moderan expresiones de autoritarismo en la sociedad.

Las epidemias a gran escala de enfermedades fatales presentan obstáculos al orden social al producir "miedo, pánico, estigma, moralización y llamadas a la acción”, efectos que son más pronunciados cuando una enfermedad es "nueva, inesperada o particularmente peligrosa" (Strong, 1990, p. 249) como es el caso de la COVID-19. Por ejemplo, desde las etapas iniciales de la actual pandemia, ha habido informes de un aumento de la violencia contra las personas afrodescendientes y minorías étnicas, como las asiáticas en Estados Unidos. Además, los grupos políticos de extrema derecha han utilizado la pandemia para promover la lucha contra la inmigración y las actitudes antimusulmanas (Aratani, 2020; Campbell, 2020).

La aprobación de las vacunas COVID-19 han generado esperanzas de que surgirá una "nueva normalidad" en 2021. Sin embargo, grupos de derechos internacionales dicen que la sociedad civil debe volver a su papel normal prepandemia para evitar una expansión permanente de poder gubernamental extralimitado (Synovitz, 2020). Transparencia Internacional ha advertido durante mucho tiempo sobre "señales preocupantes de que la pandemia dejará a su paso un mayor autoritarismo y un estado de derecho debilitado" (Transparencia Internacional, 2020). En un informe de la institución Brookings llamado Reapertura del mundo, se dice que "durante y después de la pandemia, es probable que los gobiernos utilicen crisis prolongadas para socavar la oposición interna y restringir las libertades civiles" (Hamid, 2020, p. 16).

\section{El extremismo como un efecto de la pandemia de COVID-19}

Ya se ha cumplido más de un año desde que inició el brote de coronavirus. Sin embargo, la incertidumbre sobre su continuación, una posible tercera ola y con ella, un confinamiento mucho más estricto y prolongado, así como el impacto económico sobre las personas, todo ello ha resultado en una inseguridad continua e incertidumbre para los individuos y las sociedades (Burchill, 2020, p. 5).

Con toda esta incertidumbre han aparecido sentimientos de desconfianza, insatisfacción y polarización, los sentimientos de odio y agravio se han vuelto más pronunciados a medida que las personas pretenden encontrar más certidumbre (Burchill, 2020, p. 5). En este tipo de entorno, el extremismo tanto en pensamientos y acciones pueden prosperar. La inseguridad en tiempos de crisis alimenta los sentimientos de hallar un culpable o responsable por las consecuencias negativas derivadas de la pandemia de COVID-19. Por lo tanto, los extremistas pueden aprovechar la incertidumbre y explotar las circunstancias con el fin de ganar más apoyo a sus ideologías (Burchill, 2020, p. 5).

De acuerdo con el Secretario General de la ONU, Antonio Guterres (2020), en el contexto actual de una mayor actividad y conectividad en línea generalizada, los extremistas han estado haciendo un uso efectivo de la red pues se han beneficiado de la conectividad en línea durante los últimos años.

\section{Con toda esta} incertidumbre han aparecido sentimientos de desconfianza, insatisfacción y polarización, los sentimientos de odio y agravio se han vuelto más pronunciados a medida que las personas pretenden encontrar más certidumbre 
Una de las respuestas clave a la crisis sanitaria ha sido el aislamiento de la población con la imposición de cuarentenas alrededor del mundo. Esto ha dejado a más y más personas en casa en línea, a veces completamente aisladas y ha proporcionado una audiencia casi cautiva para los grupos extremistas (Burchill, 2020, p. 9). Esto junto a la incertidumbre que sienten todas las personas a medida que el virus continúa y el futuro incierto, hace que los individuos sean más receptivos a las ideologías extremistas a las que son expuestas (Zeller, 2020). Esto lo logran al culpar a grupos externos, haciendo uso de teorías de desinformación y de conspiración, y general, tratando de demostrar que sus posiciones ideológicas son las correctas o mejores.

J. M. Berger ha proporcionado una definición de extremismo como "la creencia de que el éxito o la supervivencia de un grupo no puede separarse nunca de la necesidad de acciones hostiles contra un grupo externo" (Berger, 2018, p. 44). La idea de acción hostil es amplia, y esta puede ser desde insultos, acciones discriminatorias, violencia o la eliminación de un grupo externo. Como lo explica Berger, la necesidad de acción hostil es "incondicional e inseparable de la comprensión del éxito del grupo interno” (Berger, 2018, p. 44).

En ese sentido, para alcanzar ese nivel de aborrecimiento de otro grupo no puede haber ningún reconocimiento de que el grupo externo y sus miembros son similares en cualquier forma al grupo interno. Esto puede dar un paso más adelante para identificar el extremismo como una situación en la que uno cree que "otros" (el grupo externo) no gozan de ningún nivel de respeto o reconocimiento como seres humanos (Berger, 2018, p. 44). En ese tenor, son los elementos fundamentales del extremismo, la negación de la dignidad humana y la creencia de que el éxito y la supervivencia dentro del grupo requieren la eliminación del grupo externo que crea una atmósfera para justificar el uso de la violencia como legítima (Burchill, 2020, p. 10).

Esto supone que mientras la incertidumbre en torno al virus continúe y el descontento en relación con las respuestas para frenar la propagación del virus se acumule, el extremismo en palabras y en acciones va a tender a aumentar. Sin embargo, el extremismo estaba en aumento antes del inicio del brote de la COVID-19. Las explicaciones del virus tienden a encajar fácilmente en los mensajes centrales de los grupos extremistas. Este es el caso de Al Qaeda y Estado Islámico (ISIS) que en su discurso dicen que el virus es la voluntad de Dios para matar a los no creyentes y los enemigos (Noticias ONU, 2020).

Sorprendentemente, la dimensión de la culpa en los mensajes de los grupos extremistas atraviesa el espectro ideológico. Por ejemplo, en la India los extremistas nacionalistas hindús han culpado y han hecho responsables del virus a la población musulmana (Leidig, 2020). En Europa, los grupos antiinmigrantes de extrema derecha en Francia y Alemania han circulado información falsa diciendo que los musulmanes han estado propagando el virus a propósito y se han vinculado como la fuente del virus a los centros de asilo e inmigración (Servicio de Seguridad del Estado de Bélgica, 2020). Los funcionarios gubernamentales también han hecho responsables a grupos externos específicos, como China, como culpables de la propagación del virus, lo que ha llevado a un incremento potencial de los ataques hacia los individuos identificados como tales (Pantucci, 2020). Por otro lado, en Irán, la Guardia Revolucionaria Iraní ha incrementado sus esfuerzos de propaganda para promover teorías de conspiración antisemitas, colocando la responsabilidad del coronavirus a Israel (Tony Blair Institute for Global Change, 2020).

Tanto grupos extremistas de derecha como de izquierda, han estado llamando a tomar acciones para que ocurra el colapso de la sociedad (Burchill, 2020, p. 13). Estas llamadas, a veces descritas bajo el término "boogaloo", son sobre fomentar la violencia en la sociedad entre grupos 
diferentes, o acerca de niveles masivos de violencia generalmente de una manera que sobrepase a la policía y las fuerzas de seguridad (Coaston, 2020). Es así como muchos seguidores creen que un nuevo mundo puede ser construido con el colapso de la sociedad y el caos. Esto significa que, en tiempos de incertidumbre, las personas se sentirán atraídas por las ideas y la información, sin importar su exactitud, que apele a sus emociones (ISD, 2020). Así los extremistas pueden ampliar la narrativa en ideas para la acción y animar a los seguidores a actuar en apoyo de la ideología extremista (ISD, 2020).

\section{Factores que detonan el extremismo en tiempos de la pandemia de COVID-19}

La pandemia de COVID-19 ha provocado pérdidas y traumas a las personas. A la fecha han fallecido más de 2 millones 800 mil personas en el mundo a causa de la COVID-19 (New York Times, 2021). Pero también ha alterado los hábitos de la vida cotidiana de todas las personas en el mundo (Marone, 2021, p. 5), por ejemplo, la falta de interacciones cara a cara y el uso de las tecnologías de la información y comunicaciones (TIC) como sustituto a la socialización. La actual crisis sanitaria ha también provocado angustia psicológica en los individuos, y en general, ha causado altos niveles de incertidumbre en diferentes campos (Marone, 2021, p. 5). Como han señalado los expertos, los efectos psicológicos a corto plazo de la pandemia van desde "miedos inespecíficos y descontrolados” hasta ansiedad, frustración, aburrimiento y una sensación generalizada de soledad (Serafini et al., 2020).

Además, en el medio y el largo plazo, las consecuencias económicas, sociales y políticas de la pandemia en un nivel macro podrían crear o reforzar una serie de estados mentales negativos (Koomen y Van Der Pligt, 2015), incluidas emociones de orientación interna (como el miedo) o incluso emociones de orientación externa (como el desprecio, la ira, el resentimiento y el odio), que podrían hacer que un número mayor de personas sea más susceptible a las narrativas extremistas (Van den bos, 2020). Por otro lado, a nivel individual, los traumas personales, como la pérdida del empleo, pueden producir incertidumbre y angustia. Por tal motivo, de acuerdo con la literatura existente, hay muchos indicios de que la radicalización hacia el extremismo violento puede verse facilitada por altos niveles de incertidumbre, pérdidas personales reales o percibidas, frustración o recordatorios de la muerte, todos estos factores pueden estar asociados con la actual pandemia de COVID-19 y sus consecuencias (Ackerman y Peterson, 2020).

Estas teorías de la conspiración pueden tener consecuencias negativas. Por ejemplo, la creencia en estas teorías se ha relacionado con los movimientos antivacunas, la negación del cambio climático, las opiniones políticas extremistas y los prejuicios (Jolley et al., 2020)Study 3 ( N = 114 . Las fake news y la desinformación sobre la COVID-19 también ha proliferado ampliamente en las redes sociales, con consecuencias potencialmente peligrosas (Frenkel et al., 2020).

\section{El nacionalismo y el rol del Estado-nación ante la pandemia de COVID-19}

El 11 de marzo de 2020, Tedros Adhanom Ghebreyesus, el director general de la Organización Mundial de la Salud (OMS) anunció que la enfermedad llamada COVID-19 constituía una
La actual crisis sanitaria ha provocado también angustia psicológica en los individuos, y en general, ha causado altos niveles de incertidumbre en diferentes campos 
pandemia (Organización Panamericana de la Salud, 2020). Se hacía claro que no sería posible frenar la propagación mundial del virus y que este representaba una amenaza global a la salud, el bienestar económico y la estabilidad política de todos los países del orbe. En relación con lo anterior, muchos analistas políticos líderes sugirieron que la pandemia alimentaría el nacionalismo y el impulsor en un mundo más dividido (Legrain, 2020).

Es importante clarificar cómo entendemos a la pandemia de COVID-19, desde una perspectiva política. Esta pandemia es comúnmente descrita como una "crisis". Las crisis son provocadas por amenazas reales o percibidas (Woods et al., 2020). Son eventos altamente disruptivos (cambios en planes, rutinas, expectativas, creencias y valores) que crean una mayor incertidumbre (Brecher, 2019). Esta ruptura e incertidumbre pueden cambiar el contexto dentro del cual ocurre la política. La COVID-19 se ajusta a todos estos criterios. La amenaza planteada por la pandemia ya ha desencadenado una serie de crisis consecutivas en la salud y la economía, y también amenaza con provocar crisis en la política y cambiar el contexto nacionalista en el que ocurre gran parte de la política mundial.

Por ejemplo, naciones como China han usado la pandemia de COVID-19 para alimentar un conflicto nacionalista. Esto se puede observar en la insistencia de China de que Taiwán debe ser excluido de la OMS, con el argumento de que es parte de China, a pesar de su excelente historial en la contención de la pandemia (Reuters, 2020). Surge la pregunta si la pandemia de COVID-19 va a reforzar o erosionar el Estado-nación en el largo plazo. La respuesta parece ser que la pandemia ha permitido a los gobiernos acumular más poder de manera constante sobre sus ciudadanos (Woods et al., 2020).

En Europa y Norteamérica, se ha documentado un aumento del odio xenófobo, antiinmigrante, antiasiático y antisemita durante la pandemia de COVID-19. Un ejemplo fue la insistencia de la administración de Donald Trump en utilizar el término "virus de Wuhan" o "virus chino" como una de las "muchas estrategias para atribuir la culpa de la propagación del virus a un lugar/país específico y para construir la enfermedad como una amenaza extranjera a la nación” (Nossem, 2020). Solo en los Estados Unidos, se informaron más de 1700 incidentes de odio contra los asiáticos dentro de las primeras 6 semanas de un nuevo sitio web establecido por grupos de derechos civiles de Asia-Estados Unidos y las islas del Pacífico (Lee y Yadav, 2020). Tales expresiones xenófobas de nacionalismo son parte de un aumento claramente documentado, incluso antes del inicio de la pandemia de COVID-19, del odio extremista y de la extrema derecha.

Por otro lado, la pandemia está amplificando el sentimiento nacionalista, que está precipitando una "política de culpa" (Legrain, 2020). Esto es particularmente visible en las relaciones entre Estados Unidos y China. Una relación que ya estaba tensa ahora está empeorando rápidamente, ya que los dos países se culpan mutuamente por la pandemia y existe el temor de que estas disputas políticas puedan desembocar en conflictos violentos (Woods et al., 2020).

Las primeras señales apuntan a una tendencia a que los estados-nación aumenten enormemente su poder frente al COVID-19: están reforzando las fronteras, reduciendo la migración, limitando los movimientos internos de población, gastando grandes cantidades de dinero en estímulos económicos y aumentando la vigilancia de los ciudadanos (The economist, 2020). Muchos de estos movimientos se han producido a costa de la libertad y la privacidad individuales (The economist, 2020). Algunas de estas medidas serán relativamente de corta duración y otras probablemente serán difíciles de revertir. Independientemente, estos patrones son recientes en

\section{En Europa y}

norteamérica, se

ha documentado

un aumento del

odio xenófobo,

antïnmigrante,

antiasiático y

antisemita durante

la pandemia de

COVID-19 
el estado de nuestras vidas, devuelven al Estado la visión que teníamos de un actor poderoso. Por ejemplo, los conflictos sobre la producción y distribución de una eventual vacuna ya están tomando forma. En lugar de una colaboración y coordinación internacional concertada, estamos viendo enfoques cada vez más proteccionistas impulsados por la lógica del Estado-nación (Woods et al., 2020).

\section{Teorías de conspiración, fake neus y desinformación en la era COVID-19}

El entorno de información en medio de la pandemia de COVID-19 subraya la importancia de una comunicación científica eficaz. La crisis sanitaria ha puesto en relieve un aumento en las teorías de conspiración, noticias falsas e información errónea (Ellis, 2020). En este contexto, es más complicado para el público distinguir la evidencia y los hechos científicos de información menos confiables (Bavel et al., 2020).

Las teorías conspirativas surgieron poco después de las primeras noticias del nuevo brote de coronavirus en Wuhan China en enero de 2020 y han estado persistiendo (Ellis, 2020). Algunos se han referido a los orígenes del virus SARS-CoV-2 como un arma biológica creada por los chinos para librar la guerra con Estados Unidos o viceversa (Gertz, 2020). Otros se han centrado en la prevención y la cura, por ejemplo, que no se debe confiar en las vacunas y que las personas deben usar remedios alternativos para protegerse del virus. No es sorpresa que hayan surgido innumerables teorías de conspiración en este contexto. Los estudios sugieren que las personas sienten la necesidad de explicar grandes eventos con causas proporcionalmente grandes y es más probable que crean en teorías de conspiración sobre eventos con graves consecuencias y en tiempos de crisis (Van Prooijen y Douglas, 2017). Esto es probable que se deba a que las personas se sienten más atraídas a las teorías conspirativas cuando sus necesidades psicológicas importantes se ven frustradas (Douglas et al., 2017). Entonces, estas teorías pueden ganar mayor tracción a medida que se propaga el virus y más personas se aíslan.

\section{Conclusiones}

Si es correcto que la pandemia de COVID-19 ha reforzado al Estado-nación, entonces los ciudadanos del mundo podrían enfrentar algunos peligros. La ampliación del poder y la autonomía de los Estados-nación, junto con pocos contrapesos al interior, puede tener efectos duraderos para la privacidad, la seguridad y la democracia de todos los países. Las restricciones sanitarias como los confinamientos obligatorios han limitado las libertades de movimiento y reunión. Sin embargo, también el control de los gobiernos sobre ciudadanos ha llevado a Estados a rastrear los movimientos de los ciudadanos infectados a través de los teléfonos móviles o a prohibir las protestas ciudadanas con el uso desproporcionado de la fuerza.

La coyuntura actual de la pandemia de COVID-19 ha servido a los gobiernos autoritarios para consolidar su poder y legitimarse, mediante el recorte de libertades democráticas como el aplazamiento o la suspensión de elecciones, dar nuevas atribuciones a los militares, cerrar las fronteras a la migración y exaltar el nacionalismo frente a la cooperación internacional. Sin embargo, surge la incógnita si las medidas que han adoptado los gobiernos autoritarios 
serán derogadas una vez que haya terminado la pandemia. Organizaciones internacionales como Human Rights Watch y la ONU ya han advertido del peligro que el autoritarismo en diversos países pueda restringir los derechos humanos de las poblaciones durante la pandemia de COVID-19.

Por otro lado, el crecimiento del extremismo y los ataques terroristas durante la pandemia también son una preocupación para gobiernos del mundo. Fenómenos como el "supremacismo blanco" catalogados de extrema derecha ya son catalogados como terrorismo y una amenazada para los otros países como Reino Unido y Alemania (Aguirre, 2020). Incluso, el propio Comité de Antiterrorismo de la ONU se ha visto obligado a emitir una alerta contra la "creciente amenaza transnacional del terrorismo de extrema derecha" (Comité de Antiterrorismo de la ONU, 2020).

Por lo que se puede afirmar que hay un problema y una tendencia creciente al extremismo de derecha antes y durante la pandemia de COVID-19. Ejemplos de este fenómeno son varios, como los ataques terroristas de Oslo y Utoya, Noruega en 2011; Pitsburgh en 2018; Christchurch, Nueva Zelandia en 2019; Hanau, Alemania en 2020 o El Paso en 2020 y Atlanta en 2021 en Estados Unidos de América (Moreno, 2020) por mencionar algunos.

Se puede concluir que han sido diferentes factores los que han detonado el extremismo en el mundo, podemos citar la crisis económica de 2008 y los procesos políticos resultantes que impulsaron formaciones políticas de derecha radical, así como el sentimiento de algunos sectores opuestos a las oleadas migratorias. Sin embargo, cabe subrayar que las corrientes de extremismo de derecha son heterogéneas, y no todas comparten los mismos objetivos. Sin embargo, se pueden identificar algunos como acabar con el multiculturalismo, detener la llegada de migrantes, expulsar a los musulmanes o acabar con las élites liberales (Moreno, 2020). Durante la pandemia de COVID-19, los grupos de extrema derecha han sido más dinámicos para explotar su discurso, atraer seguidores y tomar acciones violentas principalmente a través de las redes sociales.

Se puede argumentar que la pandemia de COVID-19 ha servido también para alimentar los discursos de los grupos extremistas de derecha. Con ejemplos como la idea de que la COVID-19 es una herramienta para conseguir el "gran reemplazo", es decir, eliminar a la población blanca, otros alertan de las infraestructuras $5 \mathrm{G}$ como vehículo de transmisión, también hay teorías conspirativas sobre que el virus es un plan para hundir la economía o de que se envían inmigrantes infectados para diseminar el virus (Moreno, 2020). Por lo tanto, se puede decir que los grupos extremistas están aprovechando la actual crisis sanitaria para sembrar el caos y e intentar derrocar al sistema. Ejemplo de ello, es el denominado movimiento "boogaloo". Sin embargo, cabe mencionar que, en los países occidentales, muchos de los crímenes perpetrados por la extrema derecha se han catalogado como "crímenes de odio" y no como terrorismo.

Como conclusión, la crisis de la pandemia de COVID-19 ha actuado como combustible del populismo y del extremismo de derechas. La derecha radical alimenta el miedo y lo intensifica desde posiciones racistas e ideologías conspirativas para obtener una dominación nacionalista bajo la apariencia de "soberanía nacional". Movilizan el resentimiento y la insatisfacción entre la población, así como la incertidumbre ante el futuro y la preocupación de que el grupo nacional o étnico de referencia se encuentre en desventaja al competir con otros grupos. Sus argumentos son que la migración, la globalización y la multiculturalidad son las auténticas raíces del problema, y que se deben cortar de raíz.

\section{Se puede}

argumentar que la pandemia de COVID-19 ha servido también para alimentar los discursos de los grupos extremistas de derecha 


\section{Referencias}

Ackerman, G. y Peterson, H. (2020). Terrorism and COVID-19: Actual and potential impacts. Perspectives on Terrorism, 14(3), 59-73. https://www.universiteitleiden.nl/perspectiveson-terrorism/archives/2020\#volume-xiv-issue-3

Aguirre, M. (2020). Coronavirus: ¿por qué la pandemia de covid-19 podría fortalecer los autoritarismos y debilitar las democracias? BBC News Mundo. https:/www.bbc.com/mundo/ noticias-internacional-52184947

Amnistía Internacional. (2020). Tailandia: El cierre de medios de comunicación es una táctica de intimidación mientras aumentan las protestas. https:/www.amnesty.org/es/latest/ news/2020/10/thailand-media-outlets-shutdown-scare-tactic-growing-protests/

Aratani, L. (2020). 'Coughing while Asian': Living in fear as racism feeds off coronavirus panic. The Guardian. https://www.theguardian.com/world/2020/mar/24/coronavirus-us-asianamericansracism

Bavel, J. J. V., Baicker, K., Boggio, P. S. et al. (2020). Using social and behavioural science to support COVID-19 pandemic response. Nature Humane Behaviour, 4, 460-471 https:// doi.org/10.1038/s41562-020-0884-Z

Berger, J. M. (2018). Extremism. Boston: The MIT Press Essential Knowledge series.

Brecher, M. (2019). Crisis and Change in World Politics. New York: Routledge.

Brooks, D. (2019). Trump y Bolsonaro, a la defensa del nacionalismo en la ONU. La Jornada. https://www.jornada.com.mx/2019/09/25/mundo/026n l mun

Buckley, C. (2020). Brushing Off Criticism, China's Xi Calls Policies in Xinjiang 'Totally Correct'. The New York Times. https:/www.nytimes.com/2020/09/26/world/asia/xi-jinpingchina-xinjiang.html

Burchill, R. (2020). Extremism in the Time of COVID-19 (Bussola Research Paper N. ${ }^{\circ}$ 6). https://ssrn.com/abstract=3693293

Campbell, L. (2020). Chinese in UK report 'shocking' levels of racism after coronavirus outbreak. The Guardian. https:/www.theguardian.com/uk-news/2020/feb/09/chinese-inuk-report-shocking-levels-of-racism-after-coronavirus-outbreak

Chouza, P. (2019). Un nuevo proyecto de ley vuelve a amenazar la independencia judicial en Polonia. El País. https://elpais.com/internacional/2019/12/18/actualidad/1576681763_587693.html

Coaston, J. (2020). The "boogaloo" "movement," explained. Vox. https:/www.vox. com/2020/6/8/21276911/boogaloo-explained-civil-war-protests

Douglas, K. M., Sutton, R. M. y Cichocka, A. (2017). The psychology of conspiracy theories. Current Directions in Psychological Science, 26(6), 538-542. https://doi. org/10.1177/0963721417718261

DW. (2020). Coronavirus en Rusia: las protestas antigubernamentales se vuelven virtuales. Deutsche Welle. https://www.dw.com/es/coronavirus-en-rusia-las-protestas-antigubernamentales-se-vuelven-virtuales/a-53263518 
EFE y AFP. (2020). Estado Islámico: coronavirus es "la venganza de Alá" y rogamos por más tortura. Milenio. https://www.milenio.com/internacional/medio-oriente/estado-islamicoasegura-que-el-coronavirus-es-la-venganza-de-ala

El País. (2020). Duterte ordena disparar contra quien viole la cuarentena. https://elpais.com/internacional/2020-04-02/duterte-ordena-disparar-contra-quien-viole-la-cuarentena.html

Ellis, E. (2020). The Coronavirus Outbreak Is a Petri Dish for Conspiracy Theories. Wired. https://www.wired.com/story/coronavirus-conspiracy-theories/

Freedom House. (2020). New Report: Democracy under Lockdown - The Impact of COVID-19 on Global Freedom. https://freedomhouse.org/article/new-report-democracy-under-lockdown-impact-covid-19-global-freedom

Frenkel, S., Alba, D. y Zhong, R. (2020). Surge of virus misinformation stumps Facebook and Twitter. The New York Times. https://www.nytimes.com/2020/03/08/technology/coronavirus-misinformation-social-media.html

Gertz, B. (2020). Coronavirus may have originated in lab linked to China's biowarfare program. The Washington Times. https:/www.washingtontimes.com/news/2020/jan/26/coronavirus-link-to-china-biowarfare-program-possi/

Glenn, J. (2020). COVID-19 Brief: Impact on Democracy Around the World. U.S. Global Leadership Coalition. https://www.usglc.org/coronavirus/democracy/

Guterres, A. (2020). Secretary-General's remarks to the Security Council on the COVID-19 Pandemic. United Nations Secretary-General. https://www.un.org/sg/en/content/sg/statement/2020-04-09/secretary-generals-remarks-the-security-council-the-covid-19-pandemic-delivered

Hamid, S. (2020). "How the pandemic is reinforcing authoritarianism". En Reopening the World (pp. 16-20). Washington, D.C.: Brookings Institution.

Hartman, T. K., Stocks, T. V. A., McKay, R., Gibson-Miller, J., Levita, L., Martinez, A. P., Mason, L., McBride, O., Murphy, J., Shevlin, M., Bennett, K. M., Hyland, P., Karatzias, T., Vallières, F. y Bentall, R. P. (2021). The Authoritarian Dynamic During the COVID-19 Pandemic: Effects on Nationalism and Anti-Immigrant Sentiment. Social Psychological and Personality Science. https://doi.org/10.1177/1948550620978023

Hernández, H. (2020). La libertad de prensa, cada vez más amenazada en Turquía. Atalayar. https://atalayar.com/content/la-libertad-de-prensa-cada-vez-m\%C3\%Als-amenazadaen-turqu\%C3\%ADa

Hopkins, V. (2020). How Orban's decade in power changed Hungary. Financial Times. https:// www.ft.com/content/414f202e-9996-11ea-8b5b-63f7c5c86bef

Human Rights Watch. (2020). Azerbaijan: Relentless Crackdown on Opposition. Human Rights Watch. https:/www.hrw.org/news/2020/08/19/azerbaijan-relentless-crackdown-opposition

IDEA. (2021). Global overview of COVID-19: Impact on elections. International Institute for Democracy and Electoral Assistance. https://www.idea.int/news-media/multimedia-reports/global-overview-covid-19-impact-elections

ISD. (2020). COVID-19 Disinformation Briefing No.2. Institute for Strategic Dialogue. https:// www.isdglobal.org/isd-publications/covid-19-disinformation-briefing-no-2/ 
Jolley, D., Meleady, R. y Douglas, K. M. (2020). Exposure to intergroup conspiracy theories promotes prejudice which spreads across groups. British Journal of Psychology, 111(1), 17-35. https://doi.org/10.1111/bjop.12385

Koomen, W. y Van Der Pligt, J. (2015). The psychology of radicalization and terrorism. Abingdon: Routledge.

Leidig, E. (2020). \#CoronaJihad: How the Far-Right in India is Responding to the Pandemic. C-REX - Center for research on extremism. https://www.sv.uio.no/c-rex/english/news-andevents/right-now/2020/coronajihad-far-right-india.html

Legrain, P. (2020). The coronavirus is killing globalization as we know it. Foreign Policy. https:// foreignpolicy.com/2020/03/12/coronavirus-killing-globalization-nationalism-protectionism-trump/

Marone, F. (2021). Hate in the time of coronavirus: exploring the impact of the COVID-19 pandemic on violent extremism and terrorism in the West. Security Journal, 0123456789. https://doi.org/10.1057/s41284-020-00274-y

Martínez, J. (2020). La otra epidemia: autoritarismo y extremismo en la era del Covid-19. El Universal. https:/www.eluniversal.com.mx/opinion/javier-martinez-mendoza/la-otraepidemia-autoritarismo-y-extremismo-en-la-era-del-covid-19

Moreno, J. (2020). El silencioso repunte del "terrorismo de extrema derecha" y por qué la COVID-19 puede agravarlo. BBC News Mundo. https://www.bbc.com/mundo/noticiasinternacional-54719236

Noticias ONU. (2020). Las redes sociales, la principal arma terrorista durante la pandemia de COVID-19. https://news.un.org/es/story/2020/11/1484342

Nossem, E. (2020). The pandemic of nationalism and the nationalism of pandemics (UniGRCBS Working Paper, 8 [April]). https://doi.org/10.25353/ubtr-xxxx-1073-4da7

Organización Panamericana de la Salud. (2020). Enfermedad por el Coronavirus ॥COVID-19)" https://www.paho.org/es/enfermedad-por-coronavirus-covid-19\#: : text=El\%20Director\%20General\%20de\%20la,puede\%20 caracterizarse $\% 20$ como\%20una\%20pandemia.

Pasetti, F. (2018). Elecciones en Italia: De la retórica anti-inmigración a la violencia. Europa Press. https:/www.europapress.es/internacional/noticia-elecciones-italia-retorica-antiinmigracion-violencia-20180302085342.html

Pantucci, R. (2020). After the coronavirus, terrorism won't be the same. Foreign Policy. https:// foreignpolicy.com/2020/04/22/after-coronavirus-terrorism-isis-hezbollah-5g-wont-bethe-same/

Repucci, S. (2020). A Leaderless Struggle for Democracy. Freedom House. https://freedomhouse.org/report/freedom-world/2020/leaderless-struggle-democracy

Reuters. (2020). In Modi's India, coronavirus fallout inflames divisions between Muslims and Hindus. The Japan Times. https:/www.japantimes.co.jp/news/2020/04/20/asia-pacific/ narendra-modi-india-coronavirus-muslims-hindus/

Reuters. (2020). Taiwan says not invited to WHO meeting after China's 'obstruction'. https:// www.reuters.com/article/health-coronavirus-who-taiwan-idUSKBN27P03T 
Roth, A. (2021). Vladimir Putin passes law that may keep him in office until 2036. The Guardian. https://www.theguardian.com/world/2021/apr/05/vladimir-putin-passes-law-thatmay-keep-him-in-office-until-2036

Scott, J. (2020). Where do the UK's political parties stand on Brexit vote? BBC News. https:// www.bbc.com/news/uk-politics-55177496

Security Council Counter-Terrorism Commitee. (2020). CTED publishes Trends Alert about extreme right-wing terrorism. Naciones Unidas. https:/www.un.org/sc/ctc/ news/2020/04/01/cted-launches-trends-alert-extreme-right-wing-terrorism/

Serafini, G., Parmigiani, B., Amerio, A., Aguglia, A., Sher, L. y Amore, M. (2020). The psychological impact of COVID-19 on the mental health in the general population. QJM: An International Journal of Medicine, 2, 89. https://doi.org/10.1093/qjmed/hcaa2 01.

Servicio de Seguridad del Estado de Bélgica. (2020). The hidden danger behind COVID-19. VSSE Bélgica. https://vsse.be/sites/default/files/corona-uk-batpdf.pdf

Strong, P. (1990). Epidemic psychology: A model. Sociology of Health and Illness, 12(3), 249259. https://doi.org/10.1111/1467-9566.ep1 1347150

Synovitz, R. (2020). COVID-19 Crackdowns, Expanded Authoritarianism, And The Post-Pandemic World. Radio Free Europe-Radio Liberty. https://www.rferl.org/a/authoritarianismcrackdowns-covid-human-rights-coronavirus/31026181.html

The New York Times. (2021). Coronavirus World Map: Tracking the Global Outbreak. https:// www.nytimes.com/interactive/2020/world/coronavirus-maps.html?

Tony Blair Institute for Global Change. (2020, 11 de junio). Snapshot: How Extremist Groups Are Responding to Covid-19. https://institute.global/policy/snapshot-how-extremistgroups-are-responding-covid-19-11-june-2020

Transparency International. (2020). Will the legacy of COVID-19 include increased authoritarianism? https:/www.transparency.org/en/news/will-the-legacy-of-covid-19-includeincreased-authoritarianism\#

Van den Bos, K. (2020). Unfairness and radicalization. Annual Review of Psychology, 71, 563588. https://doi.org/10.1146/annurev-psych-010419-050953

Van Prooijen, J.W.y Douglas, K. M. (2017). Conspiracy theories as part of history: The role of societal crisis situations. Memory Studies, 10(3), 323-333. https://doi.org/10.1177/1750698017701615

Védeilhé, A., Forget, A. y Wang, C. (2020). En China, los periodistas de investigación están en vía de extinción. France 24. https://www.france24.com/es/20200922-en-foco-chinaperiodismo-de-investigacion-xi-jimping-libertad-de-expresion

Velásquez, M. (2021). México supera los 200.000 muertos por coronavirus; así se compara con Brasil y EE. UU., los únicos países que han superado esta cifra. CNN Español. https://cnnespanol.cnn.com/2021/03/26/mexico-200000-muertes-coronavirus-brasil-estados-unidos-orix/

Woods, E. T., Schertzer, R., Greenfeld, L., Hughes, C. y Miller-Idriss, C. (2020). COVID-19, nationalism, and the politics of crisis: A scholarly exchange. Nations and Nationalism, 26(4), 807-825. https://doi.org/10.1111/nana.12644

Zeller, M. (2020). Extremists thrive in times of crisis: the COVID-19 pandemic is no exception. Open Democracy. https:/www.opendemocracy.net/en/global-extremes/extremists-strivetimes-crisis-covid-19-pandemic-no-exception/ 